Ciência Florestal, Santa Maria, v. 20, n. 1, p. 177-186, jan.-mar., 2010

ISSN 0103-9954

\title{
AVALIAÇÃO DO DESEMPENHO DE OPERADORES NO TREINAMENTO COM SIMULADOR DE REALIDADE VIRTUAL FORWARDER
}

EVALUATION OF OPERATOR'S PERFORMANCE TRAINING WITH FORWARDER SIMULATOR

Eduardo da Silva Lopes ${ }^{1}$ Diego de Oliveira ${ }^{2}$ Paulo Candido da Silva ${ }^{3}$ Ademar Luiz Chiquetto ${ }^{3}$

\section{RESUMO}

O uso dos simuladores de realidade virtual é a solução mais eficiente de treinamento, permitindo capacitar os operadores rapidamente e com baixos custos. Este estudo teve por objetivo avaliar o desempenho de operadores no treinamento com o simulador de realidade virtual Forwarder. O estudo foi desenvolvido no Centro de Formação de Operadores Florestais (CENFOR), da Universidade Estadual do Centro-Oeste, estado do Paraná, Brasil. Um grupo de 26 operadores de diferentes empresas florestais foi avaliado, no qual nenhum tinha experiência na operação de máquinas, sendo avaliados os seus desempenhos em diversas variáveis operacionais. Os dados foram coletados no início e no final de cada módulo operacional do treinamento no simulador virtual. Os resultados indicaram que os operadores tiveram maior dificuldade de executar a operação de carregamento de toras, em consequência da menor visibilidade e presença de resíduos da colheita de madeira nas pilhas de toras. A maior evolução no desempenho dos operadores durante o treinamento ocorreu em relação à variável "colisão com os fueiros", com ganhos médios de 85,7 e 65,9\% nos módulos III e IV respectivamente, que contemplam as operações de carregamento de toras.

Palavras-chave: treinamento; simulador de realidade virtual; extração de madeira.

\begin{abstract}
The use of virtual reality simulators has become the most efficient solution for training, allowing the preparation of operators quickly and at low costs. This study evaluated the performance of operators undergoing training with forwarder virtual reality simulators. The study was carried out at the Forest Operators Training Center (CENFOR) at Central Western Parana State University, Parana State, Brazil. A group of 26 operators from different forest companies were evaluated. None of the operators had experience with forest machines operation, being evaluated their performance in various operations variable. Data was collected at the beginning and at the end of each training module of the virtual reality simulator. Results indicated that the operators had higher difficulty to execute the log load operation, due the small visibility and logging residues over log piles. The higher evolution in the performance of the operators during the training had been the lower impact number with the machine, with average gains of 85.7 and $65.9 \%$, in modules III and IV, respectively, which include the operations of loading logs.
\end{abstract}

Keywords: training; reality virtual simulator; log extraction.

1. Engenheiro Florestal, Dr., Professor do Departamento de Engenharia Florestal, Universidade Estadual do CentroOeste, Campus de Irati, Caixa Postal 21, CEP 84500-000, Irati (PR). eslopes@irati.unicentro.br

2. Estudante do Curso de Engenheiro Florestal, Universidade Estadual do Centro-Oeste, Campus de Irati, Caixa Postal 21, CEP 84500-000, Irati (PR). Bolsista de Iniciação Científica. diegotst2007@yahoo.com.br

3. Instrutor do Centro de Formação de Operadores Florestais, Universidade Estadual do Centro-Oeste, Campus de Irati, Caixa Postal 21, CEP 84500-000, Irati (PR). cenfor@irati.unicentro.br

Recebido para publicação em 11/08/2008 e aceito em 9/11/2009.

Ci. Fl., v. 20, n. 1, jan.-mar., 2010 


\section{INTRODUÇÃO}

A mecanização da colheita de madeira intensificou-se significativamente no início da década de 90 , ocasionado pela abertura do mercado brasileiro à importação de máquinas e equipamentos de alta tecnologia e produtividade, partindo de países de maior tradição florestal, como os escandinavos e norte-americanos (PARISE, 2006).

Segundo Lopes (2006), a mecanização trouxe vários benefícios às empresas florestais brasileiras, como maior segurança e ergonomia aos operadores, maior qualidade do produto e serviço, maior segurança na produção, viabilidade de expansão da capacidade operacional, transformação da mão-deobra, viabilização do crescimento do negócio e redução de custos de produção. Entretanto, Parise e Malinovski (2002) afirmam que, a velocidade de transição entre a utilização de equipamentos de baixa tecnologia para os de alta tecnologia e as diferenças entre as tecnologias empregadas nas máquinas e o conhecimento dos operadores foi significativa, gerando um Gap Tecnológico no processo de mecanização florestal no Brasil. As máquinas de alta tecnologia e produtividade geraram um aumento de competitividade e, em decorrência dessa mudança, foi imposta uma nova realidade na estruturação do processo, não apenas novas características para a atividade, mas, sobretudo, em relação às competências que os operadores de máquinas para a colheita da madeira devem possuir.

Segundo Machado e Lopes (2000), a etapa da extração é um dos pontos críticos da colheita da madeira, exigindo um planejamento eficiente da operação de forma a evitar pontos de estrangulamento, levando os equipamentos à sua máxima utilização e obtendo ganhos de produtividade e redução dos custos de produção. Além disso, trata-se de uma etapa influenciada por diversos fatores, como nível de experiência e habilidade do operador, condições do povoamento, características do terreno, condições climáticas, distância de extração, etc. Na extração florestal, o uso do trator florestal Forwarder tem sido intensificado, por causa da sua elevada eficiência operacional, alta capacidade de carga, baixos custos e menores danos ao meio ambiente, em especial em termos de compactação do solo, comparados aos outros sistemas de colheita da madeira utilizados no país.

Atualmente, diversas técnicas que visem a melhorar o desempenho das máquinas estão sendo desenvolvidas, a fim de maximizar a produtividade e reduzir os custos de produção. Uma das formas de melhorar a eficiência das operações é a capacitação dos operadores por meio da oferta de treinamentos, possibilitando que estes sejam capazes de utilizar as máquinas florestais na sua capacidade máxima.

Parise e Malinovski (2002) afirmam que a metodologia mais utilizada tem sido a combinação de treinamentos teóricos e práticos diretamente nas máquinas e equipamentos. Entretanto, a utilização dos próprios equipamentos no processo de treinamento nem sempre é viável, em razão dos elevados custos ocasionados pela mobilização das máquinas e equipamentos para o treinamento, os riscos de acidentes, a maior possibilidade de quebras dos equipamentos e as expectativas imediatas dos resultados de produção. Por isso, segundo Lacerda e Mazon (2002), a metodologia mais eficiente de treinamento disponível é o simulador de realidade virtual, proporcionando a capacitação de futuros operadores de forma rápida, eficiente e com baixos custos, além de evitar os acidentes, mobilização e quebra dos equipamentos (PACKALÉN, 2001).

Sendo assim, considerando a complexidade e os altos custos da extração florestal e a tecnologia dos atuais forwarders disponíveis no mercado, este estudo teve por objetivo avaliar o desempenho de operadores no treinamento com o simulador de realidade virtual.

\section{MATERIAL E MÉTODO}

\section{Área de estudo}

O estudo foi realizado no Centro de Formação de Operadores Florestais (CENFOR), do Departamento de Engenharia Florestal da Universidade Estadual do Centro-Oeste (UNICENTRO), em Irati, estado do Paraná. Os dados foram obtidos durante os treinamentos realizados para operadores de diferentes empresas florestais do Brasil, no período de outubro de 2006 a março de 2008, sendo a carga horária total do treinamento de formação de 40 horas. Foi estudada uma amostra composta por 26 operadores que não tinham nenhuma experiência na operação do Forwarder.

\section{Equipamento utilizado}

Foram utilizados dois simuladores de realidade virtuais portáteis Forwarder da Simlog Simulation 


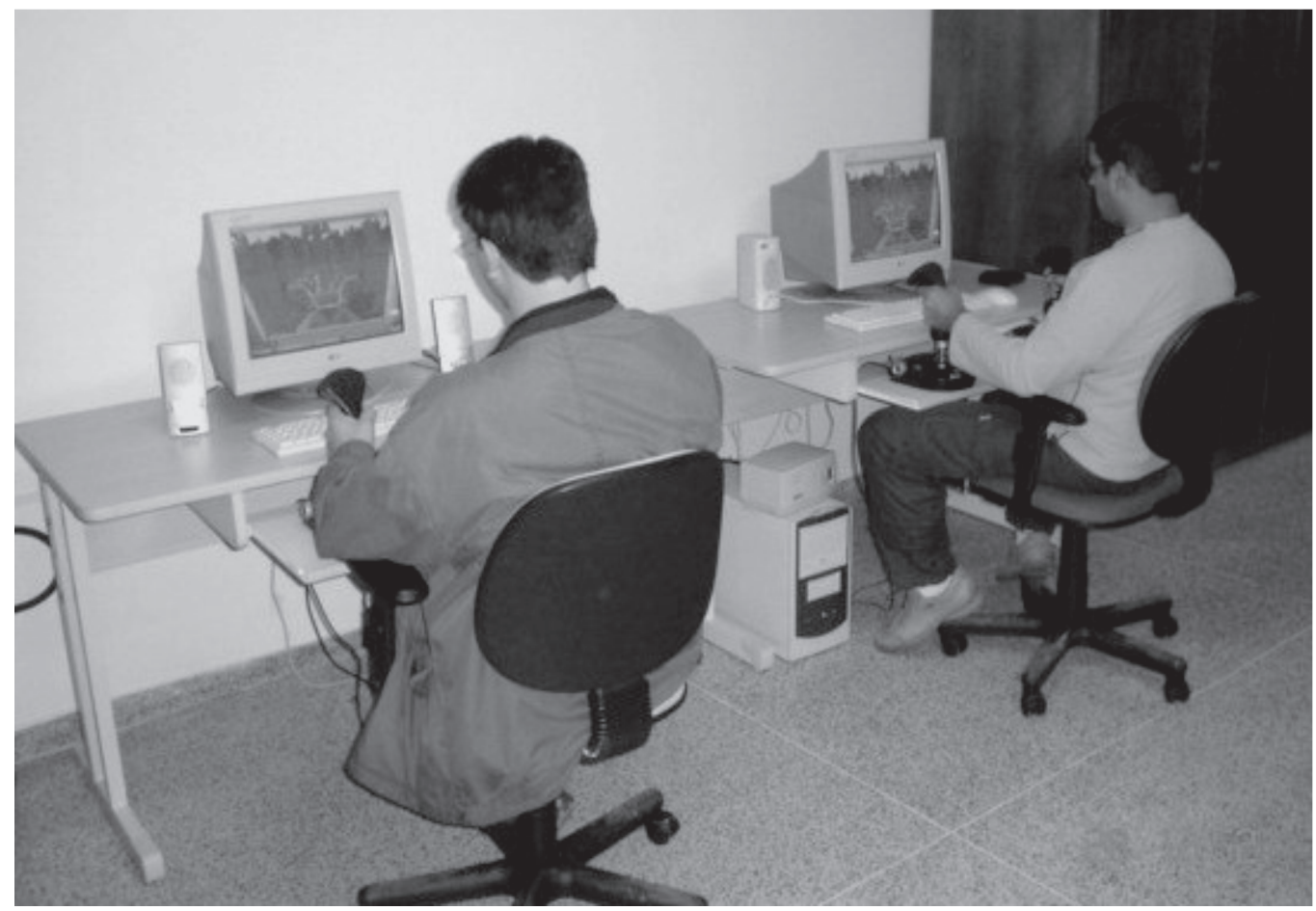

FIGURA 1: Treinamento de operadores com simulador virtual Forwarder.

FIGURE 1: Operators training with Forwarder simulator.

Launcher, equipados com “joysticks” e instalados em microcomputadores, conforme mostrado na Figura 1.

\section{Módulos avaliados}

O treinamento com o simulador de realidade virtual Forwarder (Figura 2) é composto por seis módulos operacionais. Os módulos I e II possui uma carga horária total de 12 horas e refere-se à etapa preliminar do treinamento. Os objetivos são identificar os comandos do joystick e realizar a movimentação da grua do equipamento, onde os operadores manuseam as toras dispostas sobre o terreno, a fim de adquirir as habilidades iniciais necessárias. $\mathrm{O}$ estudo contemplou apenas os dados obtidos tomando por base os módulos III a VI, com carga horária total de 28 horas, que representavam as operações de carregamento e descarregamento de toras.

A descrição dos módulos operacionais do simulador de realidade virtual Forwarder é apresentada na Tabela 1.

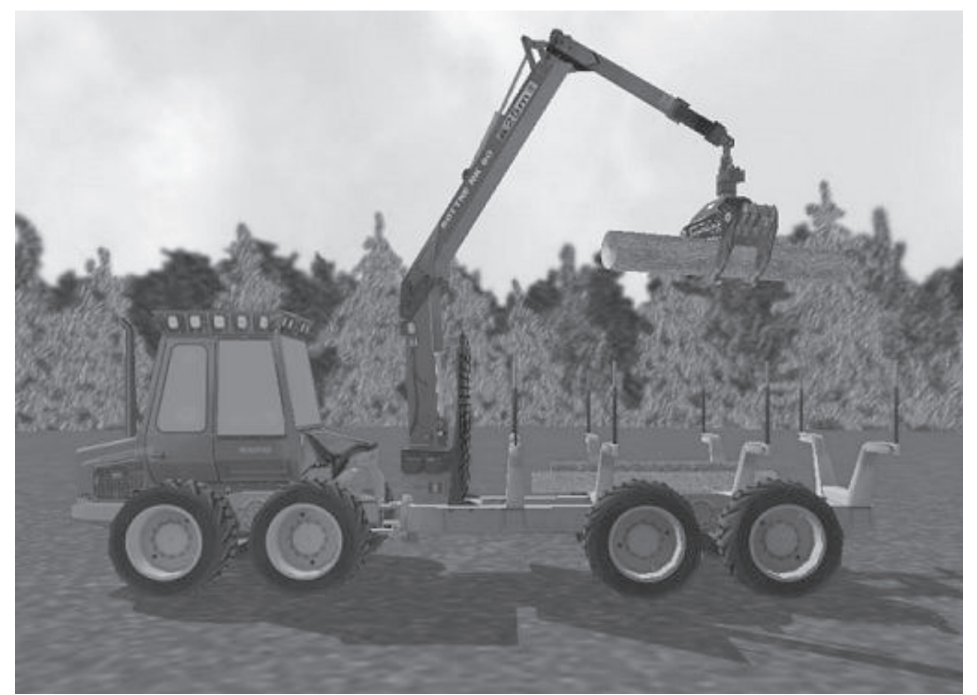

FIGURA 2: Simulador de realidade virtual Forwarder utilizado no estudo.

FIGURE 2: Virtual reality simulator Forwarder used in this study. 
TABELA 1: Descrição dos módulos do simulador de realidade virtual avaliados no estudo.

TABLE 1: Description of the modules of the reality virtual simulator evaluated in work.

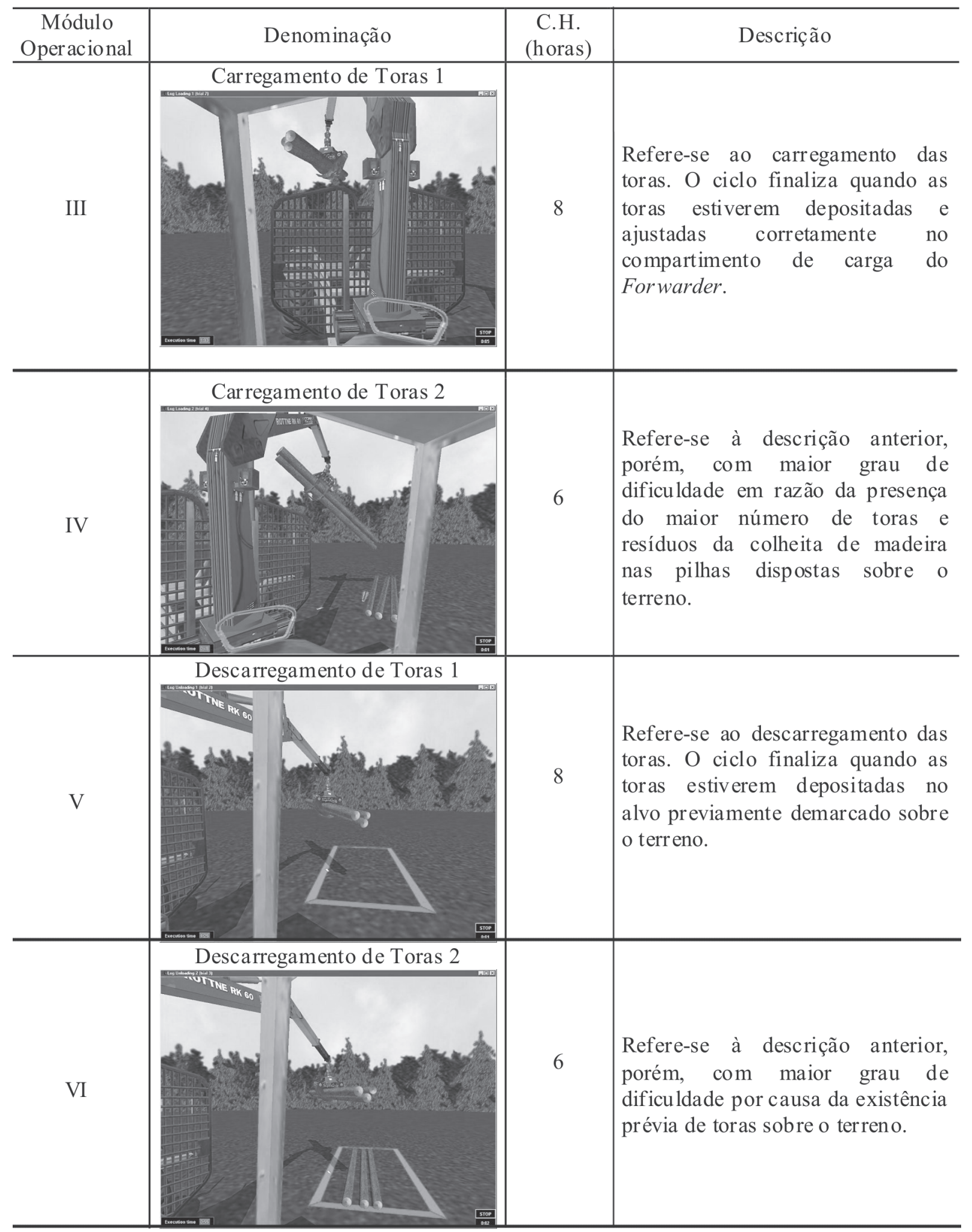

\section{Variáveis operacionais avaliadas}

O desempenho médio dos operadores em cada módulo operacional foi obtido com base em relatórios gerados pelo software do próprio simulador virtual. A Tabela 2 mostra as variáveis contempladas em cada módulo, com sua respectiva descrição. 
TABELA 2: Descrição das variáveis analisadas nos diferentes módulos operacionais.

TABLE 2: Description of the variable analyzed in the different operational modules.

\begin{tabular}{|c|c|c|c|c|c|}
\hline \multirow{2}{*}{ Variável } & \multicolumn{4}{|c|}{ Módulos } & \multirow{2}{*}{ Descrição } \\
\hline & III & IV & $\mathrm{V}$ & VI & \\
\hline \multirow{2}{*}{$\begin{array}{l}\text { Tempo de execução } \\
\text { (s) }\end{array}$} & $\mathrm{x}$ & $\mathrm{X}$ & & & $\begin{array}{l}\text { Expressa o tempo, em segundos, consumido em um } \\
\text { ciclo na operação de carregamento. }\end{array}$ \\
\hline & & & $\mathrm{x}$ & $\mathrm{x}$ & $\begin{array}{l}\text { Expressa o tempo, em segundos, consumido em um } \\
\text { ciclo na operação de descarregamento. }\end{array}$ \\
\hline \multirow{2}{*}{$\begin{array}{l}\text { Erro de Distância } \\
\qquad(\mathrm{cm})\end{array}$} & $\mathrm{x}$ & $X$ & & & $\begin{array}{l}\text { Refere-se à distância entre as toras e a grade de } \\
\text { proteção do compartimento de carga do Forwarder } \\
\text { na operação de carregamento }\end{array}$ \\
\hline & & & $\mathrm{x}$ & $\mathrm{x}$ & $\begin{array}{l}\text { Refere-se à distância entre as toras e a linha } \\
\text { pré-estabelecida sobre o terreno, na operação de } \\
\text { descarregamento. }\end{array}$ \\
\hline \multirow{2}{*}{$\begin{array}{l}\text { Erro de Alinhamento } \\
\text { (graus) }\end{array}$} & $\mathrm{x}$ & $X$ & & & $\begin{array}{l}\text { Refere-se ao alinhamento das toras no } \\
\text { compartimento de carga do Forwarder na operação } \\
\text { de carregamento. }\end{array}$ \\
\hline & & & $\mathrm{x}$ & $\mathrm{x}$ & $\begin{array}{l}\text { Refere-se ao alinhamento das toras na pilha sobre o } \\
\text { terreno, na operação de descarregamento. }\end{array}$ \\
\hline $\begin{array}{l}\text { Inclinação das Toras } \\
\text { (graus) }\end{array}$ & $\mathrm{x}$ & $X$ & $\mathrm{x}$ & $\mathrm{x}$ & $\begin{array}{l}\text { Refere-se a ângulo de inclinação das toras na garra } \\
\text { durante a operação de carregamento ou } \\
\text { descarregamento. }\end{array}$ \\
\hline $\begin{array}{l}\text { Colisão com Fueiros } \\
\qquad(\%)\end{array}$ & $\mathrm{x}$ & $X$ & $\mathrm{x}$ & $\mathrm{x}$ & $\begin{array}{l}\text { Refere-se ao percentual de colisões das toras com os } \\
\text { fueiros do compartimento de carga do Forwarder nas } \\
\text { operações carregamento ou descarregamento, sendo } \\
\text { obtido em relação ao número total de ciclos } \\
\text { operacionais realizados. }\end{array}$ \\
\hline
\end{tabular}

\section{Metas do treinamento}

Antes de iniciar o treinamento propriamente dito, foram apresentadas aos operadores as metas a serem atingidas para cada variável nos diferentes módulos operacionais. Tais metas foram estabelecidas com base na média de desempenho dos melhores operadores formados anteriormente, e que coincidiram com o desempenho dos instrutores do CENFOR.

As metas tinham por objetivo estimular os operadores a melhorarem os seus índices de desempenho, sendo que a não obtenção dessas metas não significava que os mesmos tivessem apresentado desempenho abaixo do esperado. Na Tabela 3 são apresentadas as metas para cada variável nos diferentes módulos operacionais analisados.

\section{Coleta e análise de dados}

Os dados foram coletados no decorrer do treinamento em dois períodos cronológicos distintos, partindo da média de dez simulações realizadas pelos operadores no início e ao final de cada módulo operacional, denominados de períodos pré e pós-

TABELA 3: Metas estabelecidas para as variáveis nos módulos de execução.

TABLE 3: Goals set for the variables in the execution modules.

\begin{tabular}{l|r|r|r|r}
\hline Variáveis avaliadas & \multicolumn{4}{|c}{ Módulos Operacionais } \\
\cline { 2 - 5 } & III & IV & V & VI \\
\hline Tempo de ex ecução (s) & 30 & 60 & 30 & 4 ग \\
Erro de distância (cm) & 15 & 15 & 5 & 5 \\
Erro de alinhamento (graus) & 3 & 3 & 3 & 3 \\
Inclinação das toras (graus) & 0,5 & 0,5 & 0,5 & 0,5 \\
Colisão com fueiros (\%) & 0 & 0 & 0 & 0 \\
\hline
\end{tabular}


treinamento. Para a obtenção do desempenho médio dos operadores nos treinamentos foi utilizada a seguinte expressão:

$$
g(\%)=\left(1-\left(\frac{m_{2}}{m_{1}}\right)\right) .100
$$

Em que: $\mathrm{g}(\%)=$ ganho percentual em relação ao início do treinamento na respectiva variável e módulo; $\mathrm{m}_{2}=$ média no final do módulo; $\mathrm{m}_{1}=$ média no início do módulo.

Os dados obtidos foram posteriormente analisados pela aplicação do teste " $t$ " para dados pareados, a fim de verificar se o desempenho médio obtido pelos operadores entre os períodos pré e póstreinamento nos diferentes módulos operacionais diferem estatisticamente entre si, a $95 \%$ de probabilidade.

\section{RESULTADOS E DISCUSSÃO}

\section{Variáveis analisadas}

\section{Tempo de execução}

O tempo médio consumido pelos operadores na execução do ciclo operacional de carregamento e descarregamento nos diferentes módulos operacionais do simulador virtual é mostrado na Figura 2.

Como pode ser visto, houve evolução no desempenho dos operadores entre os períodos de pré e pós-treinamento, com redução no "tempo de execução" em todos os módulos operacionais. Os operadores consumiram um maior tempo na execução da operação no módulo IV, com 108,2 segundos no período de pré-treinamento, com redução para 81,4 segundos no período de pós-treinamento. O elevado tempo consumido pelos operadores em relação aos demais módulos operacionais pode ser explicado pelo maior número de pilhas de toras dispostas sobre o terreno e pela presença de resíduos da colheita de madeira nestas pilhas. Além disso, a execução da operação de carregamento foi dificultada em razão da menor visibilidade do interior do compartimento de carga do Forwarder, exigindo maior habilidade por parte do operador.

Nos módulos III e IV, que se referem à operação de carregamento das toras, a evolução média foi de 34,8 e 24,8\%, enquanto nos módulos V e VI (descarregamento), a evolução média foi de 31,6 e $20,3 \%$ respectivamente.

O módulo VI se refere ao empilhamento das toras sobre o terreno, em local previamente determinado e com a presença de toras. Apesar da operação de descarregamento, na prática, consumir um menor tempo em relação ao carregamento, foi possível observar no simulador que essa operação também apresentou um elevado grau de dificuldade, pois, no momento do empilhamento, ocorria o "rolamento" das toras, comprometendo o tempo de execução e a qualidade das pilhas.

Apesar do maior grau de dificuldade, o tempo médio de execução foi menor em relação ao módulo anterior, mostrando que houve evolução no desempenho dos operadores no decorrer do treinamento. É importante ressaltar que, os tempos médios consumidos em todos os módulos operacionais estavam acima das metas estabelecidas para o treinamento, com exceção do módulo VI, no qual os operadores atingiram ao final da execução do módulo. Considerando que a variável "tempo de execução"

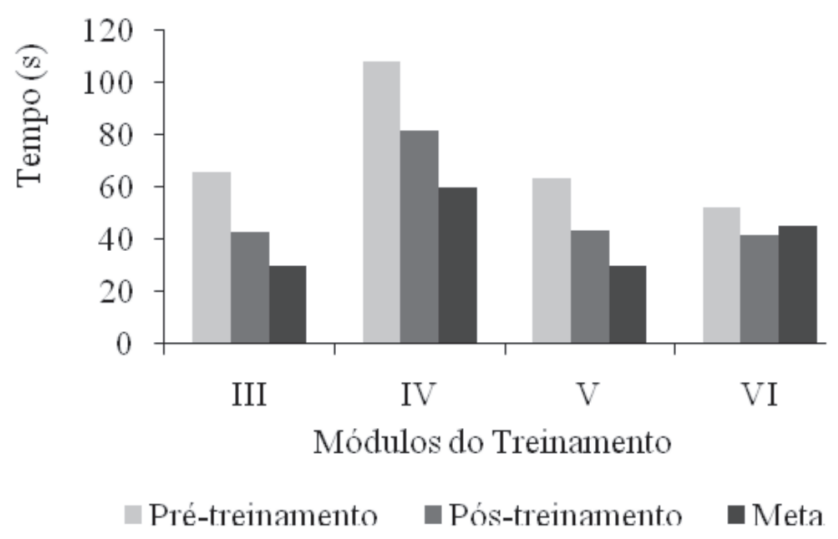

FIGURA 2: Desempenho médio dos operadores na variável "tempo de execução", em segundos.

FIGURE 2: Average performance of the operators in variable times of execution, in seconds. 
está diretamente correlacionada com a produtividade, verifica-se a necessidade de aumentar os tempos de treinamento nos módulos operacionais de carregamento e descarregamento, a fim de que os operadores possam atingir as metas estabelecidas.

\section{Erro de distância}

O "erro de distância" é uma variável que se refere à distância entre as toras e a grade de proteção do compartimento de carga do Forwarder e a distância entre as toras e a linha pré-estabelecida sobre o terreno, nas operações de carregamento e descarregamento, respectivamente. Essas operações por causa do maior grau de dificuldade de execução exigiram dos operadores maior coordenação motora e noção espacial, estando diretamente relacionada com a produtividade e qualidade da operação.

Como pode ser observado na Figura 3, o maior "erro de distância" ocorreu nos módulos III e $\mathrm{IV}$, que se referem à operação carregamento de toras, confirmando tratar-se de uma etapa com maior grau de dificuldade. Tal fato pode ser explicado pela menor habilidade dos operadores no início do treinamento e habilidade adquirida pelos operadores no decorrer do treinamento e pela maior visibilidade das pilhas de toras sobre o terreno comparado às toras no interior do compartimento de carga da máquina. $\mathrm{O}$ maior ganho de desempenho dos operadores no treinamento entre os períodos pré e pós-treinamento ocorreu no módulo III, com 48,3\%, sendo reduzida nos módulos seguintes em razão da habilidade adquirida pelos operadores. Deve-se destacar que, em situação real de operação, existe a tendência do "erro de distância" das toras serem reduzidas, tanto no compartimento de carga quanto na pilha de toras sobre o terreno, em razão da maior visibilidade da operação em condição real de campo.

\section{Erro de alinhamento}

A Figura 4 mostra o "erro de alinhamento" das toras no compartimento de carga do Forwarder e na pilha de toras sobre o terreno nos diferentes nódulos avaliados. Como poder ser visto, apenas no módulo V, os operadores não atingiram as metas estabelecidas para o treinamento.

É possível notar que, nos módulos III e IV,

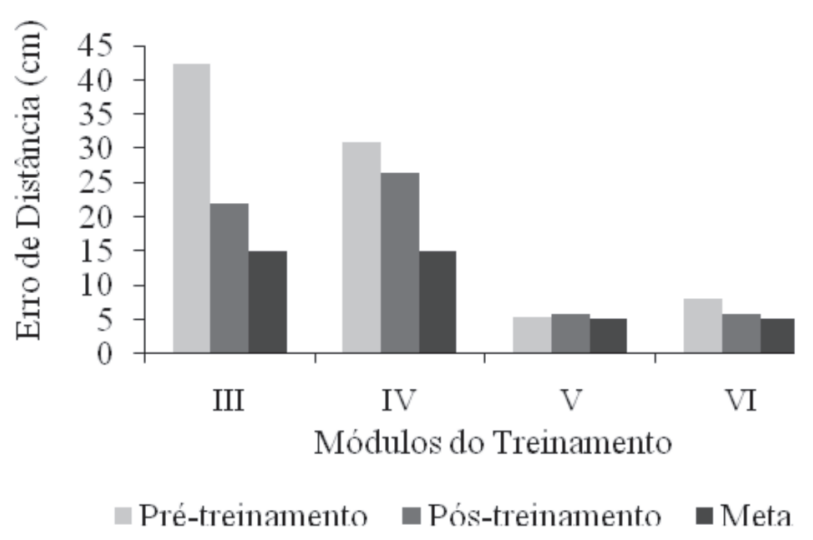

FIGURA 3: Desempenho médio dos operadores na variável "Erro de distância", em cm.

FIGURE 3: Average performance of the operators in the variable "distance error", in $\mathrm{cm}$.

menor visibilidade da operação em ambiente virtual de duas dimensões. É importante ressaltar que os operadores eram instruídos no sentido de evitar bater as toras na grade de proteção do compartimento de carga da máquina, o que é comumente observado na prática, evitando assim quebras futuras do equipamento em situação real de campo.

Por outro lado, nos módulos V e VI, o "erro de distância" foi reduzido de forma significativa, atingindo as metas estabelecidas, explicado pela que se referem à operação de carregamento, houve uma ligeira evolução no desempenho dos operadores entre o início e o final do módulo, porém, o "erro de alinhamento" foi abaixo da meta estabelecida, sobretudo no módulo IV. Essa redução do erro nos módulos pode ser explicada pela facilidade dos operadores em alinhar as toras no interior do compartimento de carga da máquina, usando como referência os fueiros e a grade proteção.

Nos módulos V e VI que se referem à 


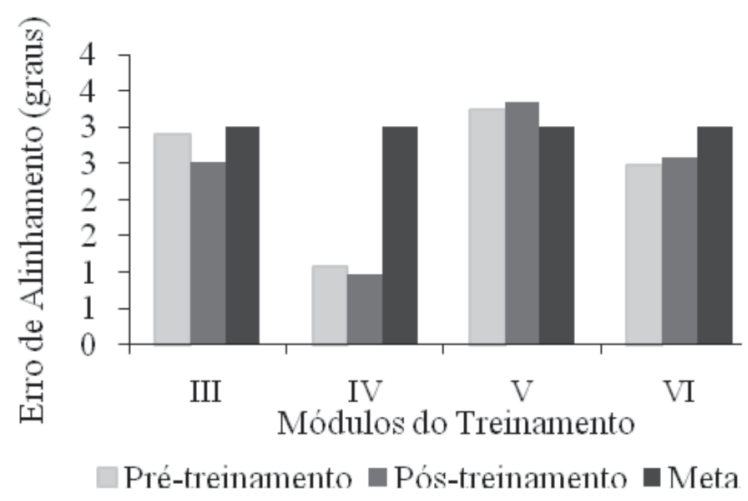

FIGURA 4: Desempenho médio dos operadores na variável "Erro de Alinhamento", em graus.

FIGURE 4: Average performance of the operators in variable error of arrangement, in degrees.

operação de descarregamento das toras sobre o terreno, houve um acréscimo médio no "erro de alinhamento" entre os períodos avaliados, ocasionados pela maior dificuldade dos operadores em realizar essa operação, comparado à operação de carregamento, mesmo com a habilidade adquirida nos módulos anteriores. Tal resultado mostra novamente a importância da ampliação da carga horária de treinamento nos módulos referente ao descarregamento, que é uma operação importante e que afeta diretamente a qualidade das pilhas de toras sobre o terreno e, consequentemente, a produtividade e os custos das operações de carregamento e transporte principal.

\section{Inclinação das toras}

A “inclinação das toras” na garra durante a movimentação da grua nas operações de carregamento e descarregamento é uma variável de grande importância na avaliação do desempenho dos operadores, estando diretamente ligada aos aspectos de segurança e desgaste do equipamento. Quanto maior o grau de inclinação, maior o risco de queda das toras e a ocorrência de acidentes, além de causar maior desgaste do equipamento, devendo, portanto, a garra se posicionar no centro de gravidade das toras no momento da execução das operações.

A Figura 5 mostra o erro de "inclinação das toras" nos diferentes módulos estudados. Como pode ser visto, em todos os módulos avaliados, o erro estava muito abaixo da meta estabelecida para o treinamento, mostrando que os operadores assimilaram facilmente a execução da operação, apanhando as toras pelo seu centro de gravidade para deposição destas no compartimento de carga da máquina ou sobre o terreno. Entretanto, foi possível observar que, os maiores erros de "inclinação de toras" ocorreram nos módulos III e IV, ocasionado pelo maior grau de dificuldade de execução da operação por causa do maior número de toras e resíduos presentes nas pilhas de madeira no momento do carregamento.

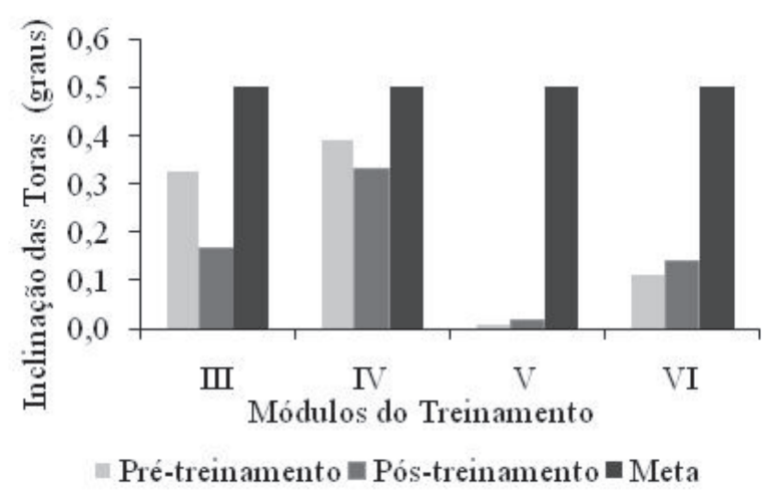

FIGURA 5: Desempenho médio dos operadores na variável "Inclinação das Toras”, em graus.

FIGURE 5: Average performance of the operators in variable inclination of logs, in degrees. 


\section{Colisão com fueiros}

A "colisão das toras" com os fueiros do Forwarder nas operações de carregamento e descarregamento é uma variável importante a ser considerada no treinamento, exigindo dos operadores maior habilidade e coordenação motora, podendo comprometer a segurança da operação e causar danos ao equipamento com o aumento de sua frequência. Considerando ser baixa a ocorrência de colisões das toras com os fueiros em treinamentos anteriores, o erro foi apresentado neste trabalho em termos percentuais, referindo-se à quantidade de colisões ocorridas no carregamento ou descarregamento em relação ao número total de ciclos operacionais realizados.

Como mostrado na Figura 6, houve um ganho no desempenho dos operadores entre os períodos avaliados, com exceção do módulo VI. O "erro de colisões" estava acima da meta estabelecida em todos os módulos operacionais, sendo maior no módulo IV ocasionado pela maior dificuldade de execução da operação de carregamento e menor visibilidade quando comparado ao descarregamento, além do erro estar correlacionado com o maior tempo consumido e inclinação das toras neste módulo.

Apesar das dificuldades encontradas, pôdese observar uma significativa evolução no desempenho dos operadores no decorrer do treinamento, cujos ganhos percentuais ao final de cada módulo foram de 85,7 e 65,9\% nos módulos III e V respectivamente. Apesar da ocorrência das colisões das toras com os fueiros do compartimento de carga ser muito baixo em relação ao número médio de 600 ciclos realizados durante o módulo de carregamento, os operadores foram instruídos para que a meta do treinamento seja atingida, ou seja, que não ocorra nenhuma colisão.

\section{Análise Estatística}

A Tabela 4 mostra o desempenho médio obtido pelos operadores nos períodos pré e póstreinamento para as diferentes variáveis e módulos estudados. Como pode ser visto, para a variável "tempo de execução", houve diferença significativa no desempenho dos operadores no decorrer do treinamento em todos os módulos analisados $(\mathrm{P}<5 \%)$. Deve-se ressaltar que no módulo VI, que se caracteriza pela operação de descarregamento com maior grau de dificuldade, o tempo médio de execução foi menor em relação ao módulo anterior, mostrando evolução no desempenho dos operadores no decorrer do treinamento.

Na variável "erro de distância", verifica-se que houve diferença significativa no desempenho dos operadores entre os períodos avaliados nos módulos III e VI, mostrando evolução dos operadores no módulo operacional de treinamento. Em relação ao "erro de alinhamento" não houve diferença significativa no desempenho dos operadores entre os períodos e módulos avaliados, explicado pelo maior grau de dificuldade dos operadores em alinhar as toras no compartimento de carga da máquina e no local de empilhamento durante as operações de carregamento e descarregamento respectivamente. Esse resultado confirmou que o período de treinamento não foi suficiente a assimilação por parte dos operadores da operação e mostrou a importância da ampliação da carga horária de treinamento em tais módulos operacionais.

Para a variável "inclinação de toras", houve diferença significativa apenas no módulo III, mostrando a maior dificuldade dos operadores no início do treinamento. Porém, com o decorrer do treinamento e prática adquirida, o erro foi reduzido.

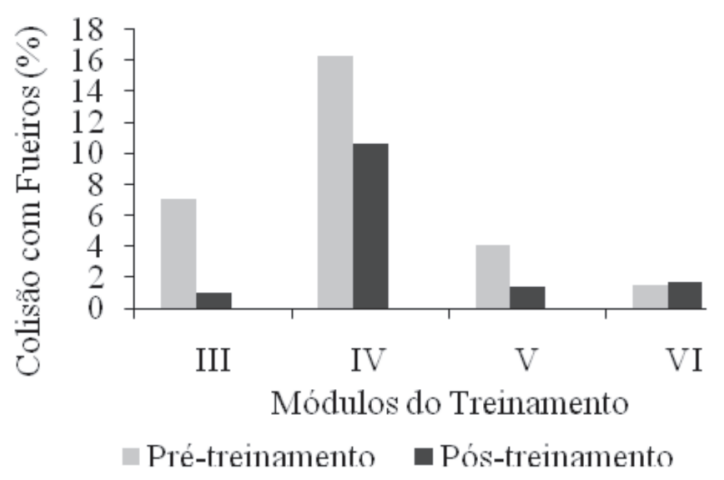

FIGURA 6: Desempenho médio dos operadores na variável "Colisão com Fueiros", em percentagem.

FIGURE 6: Average performance of the operators in variable impact with machine, in percentage. 
TABELA 4: Teste de médias para os diferentes módulos operacionais. TABLE 4: Test of averages for the different operational modules.

\begin{tabular}{|c|c|c|c|c|c|c|c|c|c|c|c|c|}
\hline \multirow{3}{*}{ Variável } & \multicolumn{12}{|c|}{ Módulos Operacionais } \\
\hline & \multicolumn{3}{|c|}{ III } & \multicolumn{3}{|c|}{ IV } & \multicolumn{3}{|c|}{$\mathrm{V}$} & \multicolumn{3}{|c|}{ VI } \\
\hline & PRÉ & PÓS & $\mathrm{t}(5 \%)$ & PRÉ & PÓS & $t(5 \%)$ & PRÉ & PÓS & $\mathrm{t}(5 \%)$ & PRÉ & PÓS & $t(5 \%)$ \\
\hline $\begin{array}{l}\text { Tempo de execução } \\
\text { (s) }\end{array}$ & 65,8 & 42,9 & $*$ & 108,2 & 81,4 & $*$ & 63,2 & 43,2 & $*$ & 51,9 & 41,3 & $*$ \\
\hline $\begin{array}{l}\text { Erro de distância } \\
\qquad(\mathrm{cm})\end{array}$ & 42,2 & 21,8 & $*$ & 30,9 & 26,3 & n.s & 5,3 & 5,8 & n.s & 8,1 & 5,7 & * \\
\hline $\begin{array}{l}\text { Erro de al inhamento } \\
\text { (grau) }\end{array}$ & 2,9 & 2,5 & n.s & 1,1 & 1,0 & n.s & 3,2 & 3,4 & n.s & 2,5 & 2,6 & n.s \\
\hline $\begin{array}{l}\text { Inclina ção das tor as } \\
\text { (grau) }\end{array}$ & 0,3 & 0,2 & $*$ & 0,4 & 0,3 & n.s & 0,0 & 0,0 & n.s & 0,1 & 0,1 & n.s \\
\hline $\begin{array}{c}\text { Colisão com fueiros } \\
(\%)\end{array}$ & 7 & 1 & $*$ & 16 & 11 & $*$ & 4 & 1 & $*$ & 2 & 2 & n.s \\
\hline
\end{tabular}

Em que: $*$ = significativo a $95 \%$ de probabilidade; $n s=$ não significativo a $95 \%$ de probabilidade.

Por fim, pode-se observar que para a variável "colisão com fueiros", houve diferença significativa no desempenho dos operadores em todos os módulos, com exceção do módulo VI, confirmando a evolução no desempenho dos operadores no decorrer do treinamento.

\section{CONCLUSÕES}

Após as análises e discussão dos resultados, a presente pesquisa permitiu concluir que:

A menor visibilidade foi a principal causa da dificuldade dos operadores em executar a operação de carregamento das toras com qualidade, comprovada pela maior incidência de "erro de distância", "erro de inclinação" e "colisões com os fueiros" do compartimento de carga da máquina, devendo a carga horária do treinamento ser ampliada neste módulo operacional.

O elevado "erro de alinhamento" das toras nas pilhas dispostas sobre o terreno no momento da operação de descarregamento afeta diretamente a qualidade, a produtividade e os custos das operações seguintes de carregamento e transporte final, devendo a carga horária do treinamento também ser ampliada neste módulo operacional.

Em todas as variáveis avaliadas, houve diferença significativa no desempenho dos operadores entre os períodos de pré e pós-treinamento, com destaque para o tempo de execução que está diretamente relacionada com a produtividade da operação.

Considerando que os operadores avaliados não possuíam experiência em operações florestais, o simulador de realidade virtual Forwarder mostrouse uma ferramenta eficiente, possibilitando contribuir para a formação de futuros operadores em menor tempo e com baixos custos.

\section{REFERÊNCIAS BIBLIOGRÁFICAS}

LACERDA, J. F. S. B.; MAZON. Uso de simuladores de realidade virtual no treinamento de operadores na colheita e transporte florestal. In: SEMINARIO DE ATUALIZAÇÃO SOBRE SISTEMAS DE COLHEITADE MADEIRA E TRANSPORTE FLORESTAL, 12., 2002, Curitiba. Anais... Curitiba: UFPR - FUPEF, p. 133-146.

LOPES, E. S. A formação de Operadores Florestais em simuladores de realidade virtuais em 3D. Revista Opiniões, São Paulo, 2006

MACHADO, C. C.; LOPES, E. S. Análise da influência do comprimento de toras de eucalipto na produtividade e custo da colheita e transporte florestal. Cerne, Lavras, v. 6, n. 2, p. 122-127, 2000.

PACKALÉN, A. Swedish study on harvester simulator training: costs cut, quality maintained. International Forestry Magazine - Timberjack News, n. 3, p. 20-21. 2001.

PARISE, D. J. Qualificação e aperfeiçoamento profissional na colheita florestal no Brasil. In: SEMINARIO DE ATUALIZAÇÃO SOBRE SISTEMAS DE COLHEITA DE MADEIRA E TRANSPORTE FLORESTAL, 14., 2006, Curitiba. Anais... Curitiba: UFPR - FUPEF, p. 191-197.

PARISE, D.; MALINOVSKI, J. R. Análise e reflexões sobre o desenvolvimento tecnológico da colheita florestal no Brasil. In: SEMINÁRIO DE ATUALIZAÇÃO SOBRE SISTEMAS DE COLHEITA DE MADEIRA E TRANSPORTE FLORESTAL, 12., 2002, Curitiba. Anais... Curitiba: UFPR - FUPEF, p. 78-109. 